\title{
Combined transurethral resection and laparoscopic paritial cystectomy for the treatment of bladder endometriosis: A case report
}

\author{
Xiaobo Huang ${ }^{1,2}$, Hubisihaletu ${ }^{3}$, Liang $\mathrm{Gu}^{3}$, Yonghua $\mathrm{Wu}^{3}$, Haiyun $\mathrm{Ye}^{1,2}$ and Qingquan $\mathrm{Xu}^{1,2 *}$ \\ ${ }^{1}$ Urology and lithotripsy Center, Peking University People's Hospital, China \\ ${ }^{2}$ Peking University Applied lithotripsy Institute, China \\ ${ }^{3}$ Department of Surgery, People's Hospital of Ijinholuo Banner, China
}

\begin{abstract} resect the mass. The final pathological result was bladder endometriosis.

\section{Background}

Bladder endometriosis is defined as the presence of endometrial glands and stroma in the detrusor muscle. The base and the dome are the most frequently affected sites. The pathogenesis, diagnosis, treatment of bladder endometriosis were peerly reviewed [1]. laparoscopic partial cystectomy is an effective technique with excellent long term results. However, this procedure may lead to inadvertent removal of healthy bladder muscle. Here, we reported a case of bladder endometriosis. The lesion was removed by a combination of transurethral resection and laparoscopic surgery.
\end{abstract}

We report a case of 44-year-old women who was found to have a bladder mass on abdomen ultrasonography. The mass was confirmed by computed tomography Cystoscopy and biopsy were performed, the pathological finding was chronic inflammation. Then laparoscopic combined transurethral surgery was performed to

\section{Case report}

A 44-year-old women was found to have a bladder mass by abdomen ultrasonograpy. She had a previous history of Cesarean delivery and Hysterectomy. Cystoscopy and biopsy was performed and found that the mass located within the posterior bladder wall and was covered with mucosa. The pathological finding was chronic inflammation. Then she was refered to our hospital. The contrast CT scan confirmed the location of the mass. The mass contained solid and cystic components and protruded into the bladder lumen. We decided to perform partial cystectomy combined of transurethral resection technique.

Under general anesthesia, the patient was set in lithotomy position. The pneumoperitoneum was obtained by Veress needle technique. The laparoscopic procedure was performed transperitoneally with a three-port arrangement. A $10 \mathrm{~mm}$ trocar was inserted above the umbilical scar. The $30^{\circ}$ laparoscope was inserted. Two $12-\mathrm{mm}$ trocars were introduced in the right and left lower quadrant of the abdomen under vision respectively. The adhesion of omentum with bladder with released by ultrasonic scissors at first. A transurethral Colling's knife was used to make a circumferential mucosomuscular incision around the mass (Figure 1). It's very easy to locate the resection line by turning off the light of laparoscope (Figure 2). The mass was completely

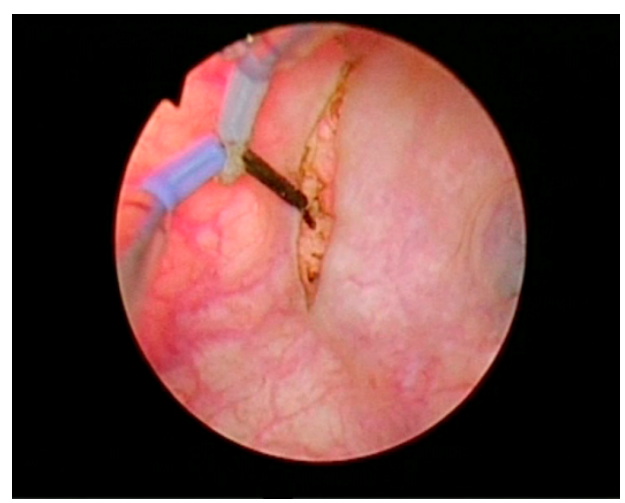

Figure 1. Cystoscopic view. A transurethral Colling's knife was used to make a circumferential mucosomuscular incision around the mass

removed around the line with ultrasonic scissors (Figure 3). The defect of the bladder wall was closed by running suture with 3-0 V-lck sutures (Figure 4). The urethral catheter was removed on day 7 postoperatively. Endometrial gland and stroma were found on pathological study and bladder endometriosis was confirmed.

\section{Discussion}

Endometriosis is defined by the presence of endometrial glandular epithelium and stroma implants in extra-uterine location. Endometriosis is a common gynecologic disease affecting women of reproductive age. The estimates of incidence of endometriosis vary from

${ }^{\star}$ Correspondence to: Qingquan $\mathrm{Xu}, \mathrm{MD}$, Urology and Lithotripsy Center, Peking University People's Hospital, 133 Fuchengmennei Street, Beijing, 100034, China, Tel: 86-10-66583720,E-mail: xuqingquan@pkuph.edu.cn

Key words: bladder, endometriosis, laparoscopic, transurethral, partial cystectomy Received: February 20, 2019; Accepted: May 28, 2019; Published: June 01, 2019 


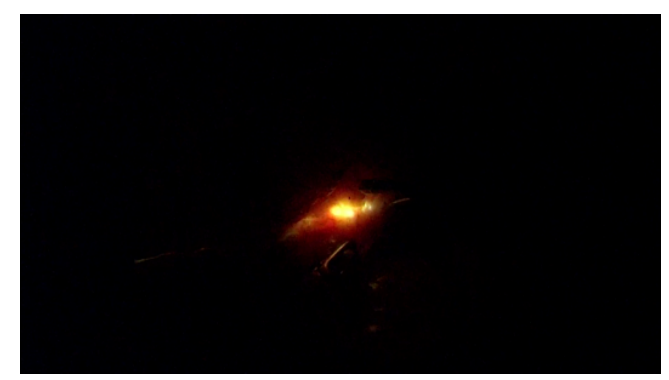

Figure 2. Laparoscopic view. Locate the marked line by switching off the light of laparoscope

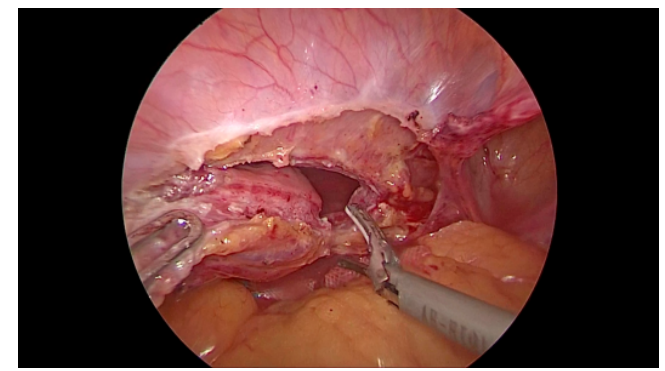

Figure 3. Laparoscopic view. The mass was removed en bloc around the line with ultrasonic scissors

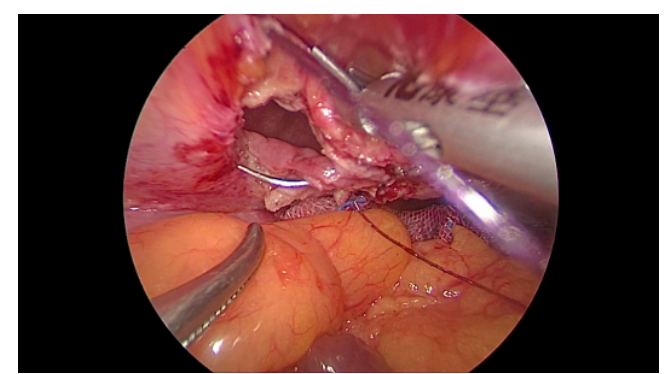

Figure 4. The defect of the bladder wall was closed by running suture with a 3-0 V-lck sutures

$<10 \%$ t0 $>20 \%$ of women [2]. Typical sites include the ovaries, fallopian tubes, pelvic peritoneum, and uterosacral ligaments. The atypical sites of endometriosis involves gastrointestinal tract, urinary tract, abdomen wall, chest and adrenal [3-5]. Urinary tract endometriosis accounts for $0.2 \%$ of endometriosis in a retrospective review of 1376 pathologic reports [5]. Although considered rare, endometriosis of the urinary tract might be more common than previously thought owing to changing definition and a lack of recognition by surgeons [2]. bladder involvement is the most frequent type of urinary tract endometriosis, occurring in $70 \%-85 \%$ of cases [1]. Audebert and colleague reported the anatomic distribution of endometriosis. In their series, bladder was the site of superficial implants or endometriotic nodes in $21.5 \%$ patients [6]. Most bladder endometriosis patients present with lower urinary tract symptoms, haematuria. The symptoms may worsen during menstruation [1].
The pathophysiology of endometriosis remains elusive. Retrograde menstruation is the most commonly accepted theory. Other theories include coelomic metaplasia, dysregulation of the immune system and iatrogenic endometriosis implant [2].

Treatment options are considered based on symptom and the site of the lesions. Hormonal therapy is generally used for temporary relieving the symptom. And surgical excision of the lesion is the treatment of choice [2]. Laparoscopic partial cystectomy is the preferable surgery for bladder endometriosis. It is difficult to identify the correct margin of the lesion during procedure [2]. At this time, combining cystoscopy could quickly locate and ensure the correct margins. Different authors have described the combination of cystoscopy and laparoscopy for bladder endometriosis resection [7-11]. We made a circumcision line around the lesion with a transurethral collings's knife. The margin of the lesion could be easily found by switching off the light of the laparoscope. The lesion could be removed en bloc just following the marking line. This combination strategy made the procedure safe and efficacious.

\section{References}

1. Leone Roberti Maggiore U, Ferrero S, Candiani M, Somigliana E, Vigano P, et al (2017) Bladder Endometriosis: A Systematic Review of Pathogenesis, Diagnosis, Treatment, Impact on Fertility, and Risk of Malignant Transformation. Eur Urol 71: 790-807. [Crossref]

2. Nezhat C, Falik R, McKinney S, King LP (2017) Pathophysiology and management of urinary tract endometriosis. Nat Rev Urol 14: 359-372. [Crossref]

3. Sonavane SK, Kantawala KP, Menias CO (2011) Beyond the boundaries-endometriosis typical and atypical locations. Curr Probl Diagn Radiol 40: 219-232. [Crossref]

4. Joseph J, Sahn SA (1996) Thoracic endometriosis syndrome: new observations from an analysis of 110 cases. Am J Med 100: 164-170. [Crossref]

5. Lee HJ, Park YM, Jee BC, Kim YB, Suh CS (2015) Various anatomic locations of surgically proven endometriosis: A single-center experience. Obstet Gynecol Sci 58: 53-58. [Crossref]

6. Audebert A, Petousis S, Margioula-Siarkou C, Ravanos K, Prapas N, et al. (2018) Anatomic distribution of endometriosis: A reappraisal based on series of 1101 patients. Eur J Obstet Gynecol Reprod Biol 230: 36-40. [Crossref]

7. Perez-Utrilla Perez M, Aguilera Bazan A, Alonso Dorrego JM, Hernandez A, de Francisco MG, et al. (2009) Urinary tract endometriosis: clinical, diagnostic, and therapeutic aspects. Urology 73: 47-51. [Crossref]

8. Roman H, Arambage K, Pasquier G, Resch B, Huet E (2014) Combined cystoscopic and laparoscopic approach in deep endometriosis of the bladder. J Minim Invasive Gynecol 21: 978-979. [Crossref]

9. Litta P, Saccardi C, D'Agostino G, Florio P, De Zorzi L, et al. (2012) Combined transurethral approach with Versapoint((R)) and laparoscopic treatment in the management of bladder endometriosis: technique and 12 months follow-up. Surg Endosc 26: 2446-2450. [Crossref]

10. Pang ST, Chao A, Wang CJ, Lin G, Lee CL (2008) Transurethral partial cystectomy and laparoscopic reconstruction for the management of bladder endometriosis. Fertil Steril 90: 2014. e1-3. [Crossref]

11. Sener A, Chew BH, Duvdevani M, Brock GB, Vilos GA, et al. (2006) Combined transurethral and laparoscopic partial cystectomy and robot-assisted bladder repair for the treatment of bladder endometrioma. J Minim Invasive Gynecol 13: 245-248. [Crossref]

Copyright: (C2019 Huang X. This is an open-access article distributed under the terms of the Creative Commons Attribution License, which permits unrestricted use, distribution, and reproduction in any medium, provided the original author and source are credited. 